\title{
Alterações nos atributos de um Latossolo Vermelho-amarelo irrigado com água de reúso ${ }^{1}$
}

\author{
Antonio C. T. Varallo ${ }^{2}$, Letícia Carvalho ${ }^{3}$, Bruno L. Santoro ${ }^{3} \&$ Claudinei F. Souza ${ }^{4}$
}

RESUMO

\begin{abstract}
A reutilização do efluente de esgoto tratado para suprir a falta de fontes d'água para irrigação tem sido de grande interesse para a agricultura e o uso desta prática, se não regulamentado, pode acarretar em mudanças no comportamento físico e químico do solo. O bjetivou-se, neste trabalho, a avaliação das alterações dos atributos físico-químicos de um Latossolo Vermelho amarelo, após a aplicação da água de reúso proveniente de uma estação de tratamento de efluentes por leitos cultivados. Um experimento em coluna de solo foi realizado em laboratório; $15 \mathrm{~L}$ de água destilada lhe foram aplicados e, logo após, mais $15 \mathrm{~L}$ de água de reúso e, a cada $5 \mathrm{~L}$, foi coletada amostra da água lixiviada para análises. 0 s resultados mostraram, após a aplicação no solo, da água de reúso, redução de nitrato, potássio e valores da condutividade hidráulica saturada e aumento das concentrações de sódio, ferro, manganês, zinco e condutividade elétrica. Pode-se concluir, desta forma, que a utilização de água de reúso para fins agronômicos deve ser de forma racional, monitorando-se principalmente a elevação do teor do íon sódio.
\end{abstract}

Palavras-chave: irrigação, salinidade, sódio

\section{Alterations in attributes of a Red-yellow Latosol irrigated with reuse water}

\begin{abstract}
The reuse of treated sewage effluent to water bodies to supply water for irrigation has been of great advantage to agriculture, and the use if not regimented could bring changes in physical and chemical properties of soil. This paper aimed the evaluation of the physical and chemical properties alteration of a Red-yellow Latosol after the application of reuse water from an effluent treatment station of wetlands. The experiment was accomplished in laboratory using a soil column. First, $15 \mathrm{~L}$ of distilled water were applied in the soil column and after $15 \mathrm{~L}$ of reuse water and at interval of $5 \mathrm{~L}$ of water a sample was collected for analysis. The results showed decrease of nitrate, potassium and saturated hydraulic conductivity values and an increase in sodium, iron, manganese, zinc and electrical conductivity of the soil after water application. In this way, it may be concluded that the use of waste water for agronomic activities must be used in a rational way, mainly checking the elevation of sodium.
\end{abstract}

Key words: irrigation, salinity, sodium

\footnotetext{
${ }^{1}$ Parte da Dissertação de Mestrado do primeiro autor.

2 Departamento de Engenharia Civil/Ambiental - UNITAU. Rua Expedicionário Ernesto Pereira 99, Centro, CEP 12020-330 Taubaté, SP - CEP 12020-330. , Fone: (12) 3625-4294. E-mail: antonio.varallo@unitau.br

${ }^{3}$ Engenheiro Ambiental e Sanitarista. Fone: (12) 9137-3247. E-mail: blsantoro@hotmail.com

${ }^{4}$ DRN PA/UFSCar. Rodovia Anhanguera, Km 174 - SP - 330, CEP 13600-970 Araras, SP. - CEP 13600-970 Fone: (19) 3541-2688. E-mail: cfsouza@cca.ufscar.br
} 


\section{INTRODUÇãO}

Segundo Mancuso et al. (2003) do total de água existente no planeta mais de $99 \%$ não servem para o consumo humano ou têm custo bastante elevado quando se fala em sua exploração. Da água consumida $65 \%$ são utilizados na agricultura, $25 \%$ na indústria e $10 \%$ para fins urbanos. Na maioria das vezes esta água é, depois de usada, descartada no meio ambiente, em forma de esgoto com ou sem tratamento.

A água de reúso, que é a água residuária já dentro dos padrões mínimos exigidos para utilização, quando lançada -no solo é, também, uma prática das mais antigas conhecidas pelo homem, segundo Mehnert (2003). De acordo com Reis et al. (2005) a reutilização da água concorre adequadamente para sua sustentabilidade cuja utilização na agricultura é uma forma alternativa de controle das fontes poluidoras nos corpos d'água, além da reciclagem dos nutrientes e aumento da produção agrícola.

A prática de irrigação com águas de reúso, feita de maneira criteriosa, não só fornece os nutrientes para a cultura a que se destina mas é uma forma de tratamento e limpeza quando de sua passagem pelo solo alimentando, com isto, o lençol freático, conforme Araújo et al. (1999).

Dentre outros motivos, para a utilização da água de reúso para fins agrícolas se destacam, ainda: o custo elevado dos fertilizantes e seus riscos para a saúde pública e para o solo, a quase não existência de fontes alternativas visando à irrigação de culturas, o elevado custo dos sistemas de tratamentos de esgotos para sua descarga em corpos receptores de efluentes e, sobretudo, a importância e o valor da prática da gestão de recursos hídricos atualmente reconhecidos pelos orgãos gestores desta prática, segundo Hespanhol (2003).

É notório o fato de que esgotos domésticos, quando reusados sem o devido tratamento, podem contaminar o ambiente com bactérias, parasitas e vírus, afetando trabalhadores e consumidores de culturas irrigadas, conforme mencionado por Souza et al. (2001). Segundo Bond (1998), se mal planejada, a aplicação de água de reúso no solo poderá causar problemas, principalmente com respeito à contaminação do solo e do lençol freático por nitratos, compostos orgânicos, sodicidade, salinidade e metais pesados.

Pesquisadores têm elaborado -inúmeros trabalhos analisando os efeitos da sodicidade e salinidade sobre as modificações nas propriedades físico-hídricas do solo e suas consequências na porosidade, permeabilidade, capacidade de infiltração e retenção de água.

Outro fator significativo é o excesso de sal na água, que provoca diminuição de absorção de água pela planta e degrada as características físicas do solo. A salinidade de um solo ocorre pela medição da condutividade elétrica (CE) do extrato de saturação do solo, caso em que um dos íons mais importantes a serem estudados é o sódio que, em excesso, diminui a permeabilidade do solo reduzindo as taxas de infiltração e cujo efeito é avaliado através do cálculo da taxa de adsorção de sódio - RAS.

Como a porosidade de um solo representa uma porção por onde circulam água, nutrientes e ar, seu estudo é uma das maneiras de se determinar as características do comportamento físico-hídrico do solo mediante a distribuição do diâmetro de seus poros.

A magnitude da macroporosidade foi enfatizada por Reichardt \& Timm (2004) no que diz respeito à condutividade hidráulica do solo saturado $\left(\mathrm{K}_{0}\right)$. A condutividade hidráulica de um solo seria a velocidade com que um líquido atravessa um meio poroso. De acordo com Reichardt \& Timm (2004), a influência das condições físicas do solo sobre o transporte de nutrientes está relacionada: (i) à umidade do solo que, quando adequada, gera transpiração potencial das plantas arrastando os nutrientes por um fluxo até a superfície radicular; altos teores de água no solo afetam o crescimento radicular em função do prejuízo do processo de aeração do solo; por outro lado, baixos teores de água também causam danos ao desenvolvimento radicular da planta; além disso, o índice de umidade afeta o comportamento mecânico do solo, o que acaba gerando efeitos na penetração das raízes; (ii) à aeração - inversamente proporcional à quantidade de água no solo e interage com as atividades dos micro-organismos, tão essenciais à nutrição das plantas quanto à respiração radicular; (iii) à textura de um solo que, de acordo com o tamanho de suas partículas, será fundamental na determinação de suas propriedades hídricas que, em consequência, afetam os processos de fluxo de massa, interceptação radicular e absorção dos nutrientes pelo sistema radicular das plantas.

O nível de fertilidade de um solo depende de sua capacidade de fornecer água e nutrientes para o desenvolvimento adequado das plantas, influenciado pelas propriedades físicas, químicas e biológicas do solo. Para fins práticos, o nível de fertilidade de um solo é avaliado por um conjunto de propriedades químicas: $\mathrm{pH}$ (acidez ativa), matéria orgânica, fósforo, potássio, cálcio, magnésio, alumínio + hidrogênio (acidez potencial), capacidade de troca catiônica (CTC), saturação por bases, etc., ainda de acordo com Reichardt \& Timm (2004).

Miranda et al. (2007) afirmam ser indispensável uma ação de reutilização da água para a sustentabilidade de atividades produtivas. Fiori et al. (2007) ressaltam que o réuso da água tem ótimos resultados nas condições estruturais do solo diminuindo a compactação e, em contrapartida, aumentando sua capacidade de aeração; já Baumgartner et al. (2007) confirmam alterações químicas no solo porém proporcionais às características das águas utilizadas.

De acordo com Blum (2003), quando a água possui turbidez elevada há indícios de teores elevados de sólidos supensos que podem abrigar micro-organismos; sendo assim, uma monitoração da turbidez se faz necessária no controle da proliferação desses micro-organismos que podem acarretar prejuízos ao ser humano como consumidor da cultura na qual se utilizou a água de reúso para o desenvolvimento.

Faz-se necessário, portanto, um estudo mais profundo quando da aplicação de água de reúso no solo, diante das consequências que este fato poderá provocar nas propriedades físicas e químicas, gerando danos não apenas para a cultura - quando de sua aplicação para fins agrícolas, mas também poderá causar degradação do solo e danos ao meio ambiente, em geral. 
O presente trabalho tem como objetivo, avaliar as alterações nos atributos físicos e químicos de um Latossolo Vermelho-amarelo, após a aplicação de água de reúso.

\section{MATERIAL E MÉTODOS}

Amostras de um Latossolo Vermelho-amarelo distrófico classificado conforme EMBRAPA (1999) foram retiradas em uma profundidade de 0-30 cm, de uma área pertencente ao Departamento de Ciências Agrárias da Universidade de Taubaté, Estado de São Paulo, com Latitude de 23 01' 51,7" S e Longitude de $45^{\circ} 30^{\prime} 37,4^{\prime \prime} \mathrm{W}$ e elevação de $553 \mathrm{~m}$. Uma porção dessas amostras foi utilizada em ensaios para determinação das características físico-químicas do solo natural, antes da aplicação de água de reúso. O restante do solo foi secado ao ar e passado em peneira com malha de $2 \mathrm{~mm}$ (TFSA), acomodado em um módulo hidráulico, do tipo coluna de solo, conforme pode ser observado no esquema na Figura 1, montado no Laboratório de Mecânica de Solos no Departamento de Engenharia Civil, na Universidade de Taubaté, SP.

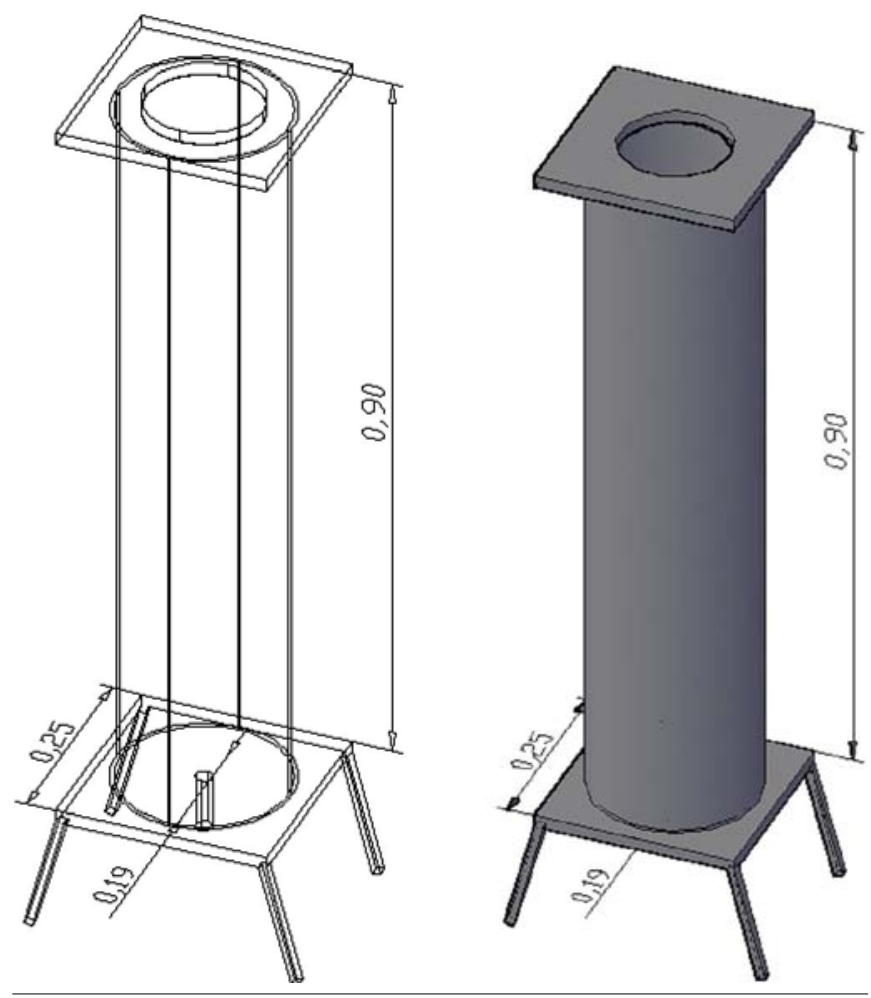

Figura 1. Esquema do módulo hidráulico do tipo coluna de solo

O módulo hidráulico de simulação de escoamento em meios porosos se compõe de uma coluna de acrílico com diâmetro de $19 \mathrm{~cm}$ e altura de $90 \mathrm{~cm}$. Esta coluna possui uma pequena abertura na parte inferior para permitir a saída e o movimento da água. Escolheu-se o acrílico visto que, além de se tratar de um material inerte, permite o acompanhamento da acomodação do solo e a visualização de molhamento.

A montagem do módulo foi realizada da seguinte forma: inicialmente, a coluna de acrílico (corpo do módulo hidráulico) foi colocada sobre um suporte metálico, facilitando o fun- cionamento do dreno da água utilizada para a saturação do meio poroso. Uma pinça de Mohr faz o fechamento deste dreno. Para auxiliar na melhor distribuição da água pelo meio poroso, tanto na saturação do solo como na condução do experimento colocou-se, no fundo desta coluna, uma manta têxtil do tipo "Bidin" para impedir a passagem do solo pelo dreno. Visando à colocação do solo de forma homogênea dentro da coluna utilizou-se um cano de PVC 3/4" acoplado a um funil. $\mathrm{O}$ solo foi adicionado aos poucos, distribuído de forma uniforme dentro da coluna procurando-se reproduzir, o mais próximo possível, a densidade do solo de campo. O módulo hidráulico foi dividido em seis partes iguais de $15 \mathrm{~cm}$ e colocados, em cada parte, $6,52 \mathrm{~kg}$ do solo peneirado, totalizando $39,12 \mathrm{~kg}$ e, consequentemente, mantendo a densidade do solo em $1,5 \mathrm{~kg} \mathrm{~m}^{-3}$.

Com vistas à simulação do movimento de água dentro da coluna utilizou-se um frasco de Mariotte que viabiliza uma carga hidráulica prédefinida. A Figura 2 mostra o início da saturação do solo e a passagem da água do frasco de Mariotte para a coluna.

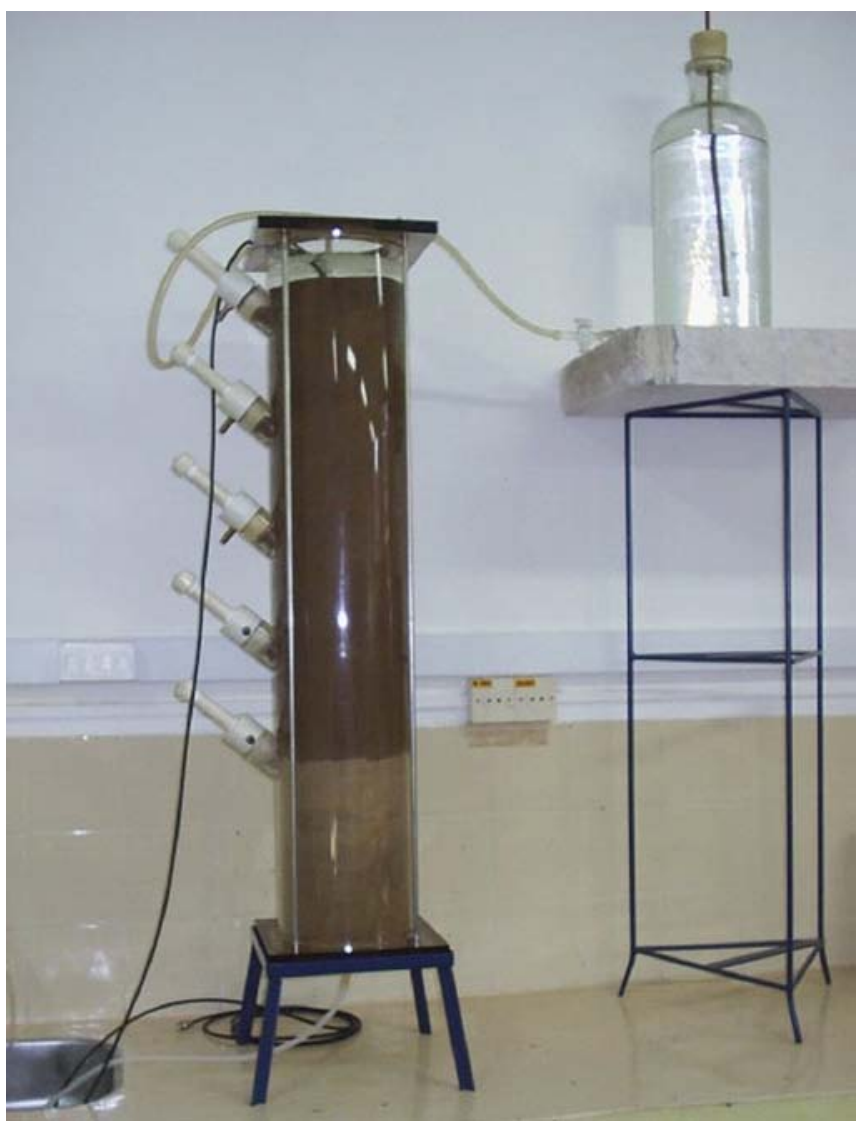

Figura 2. Início da saturação do solo mostrando a passagem da água do frasco de Mariotte para a coluna

Na coluna se instalou a uma altura de $50 \mathrm{~cm}$, uma sonda contínua de TDR posicionada na parte central do módulo hidráulico, que permitiu o monitoramento dinâmico dos valores de condutividade elétrica (CE) do solo durante a aplicação do efluente. A sonda foi construída e calibrada segundo as metodologias propostas por Souza et al. (2006a; 2006b) e Mmolawa \& Or (2000). Formada de três hastes de aço conec- 
tadas a um cabo coaxial RG58-50\&!, esta sonda foi acoplada a um Reflectômetro TDR100 (Campbell Scientific, Logan-Utah) equipado com uma interface RS232, que analisa o sinal eletromagnético automaticamente, através de um coletor de dados (CR1000-Dataloger-Campbell Scientific).

A quantidade de água aplicada no experimento foi baseada na necessidade de consumo para o cultivo de 2 ciclos da cultura da alface "Elisa" (Lectuca sativa L.). A lâmina de consumo de água foi encontrada por Santos \& Pereira (2004), aproximadamente $150 \mathrm{~mm}$ por ciclo.

A água de reúso utilizada foi coletada em uma estação de tratamento de esgoto compacta por leito cultivado implantada no Viveiro de Plantas Municipal de Jacareí, SP, nas coordenadas geográficas com Latitude $45^{\circ} 58^{\prime} 1,63^{\prime \prime} \mathrm{S}$ e Longitude $23^{\circ} 18$ ' $50,34 " \mathrm{~W}$. O efluente bruto gerado provém de banheiros utilizados por funcionários e visitantes, cujas características são apresentadas na Tabela 1, conforme descrito por Ribas \& Fortes Neto (2006). Ainda segundo os pesquisadores, o sistema de tratamento utilizado - leito de raízes cultivado apresentou boa eficiência no tratamento do efluente bruto gerando um efluente tratado dentro dos limites estabelecidos pela legislação, no que diz respeito à aplicabilidade de reúso.

Tabela 1. Características da água de reúso

\begin{tabular}{|c|c|}
\hline Parâmetros & Resultados \\
\hline DBO & $74,0 \mathrm{mg} \mathrm{L}^{-1}$ com redução de $86,6 \%$ \\
\hline DQO & 149,2 mg L-1 com redução de $87,0 \%$ \\
\hline $\mathrm{pH}$ & 6,9 \\
\hline Nitrogênio amoniacal & $30,6 \mathrm{mg} \mathrm{L}^{-1}$ \\
\hline Nitrogênio total Kjeldahl & $44,0 \mathrm{mg} \mathrm{L}^{-1}$ \\
\hline Fosfato total & $5,4 \mathrm{mg} \mathrm{L}^{-1}$ com redução de $38 \%$ \\
\hline Coliformes fecais totais & 15.000 NMP em $100 \mathrm{~mL}$ com redução de $99 \%$ \\
\hline Coliformes termotolerantes & $10.000 \mathrm{NMP}$ em $100 \mathrm{~mL}$ \\
\hline RAS & $\left(0,85 \mathrm{mmol} \mathrm{L}^{-1}\right) 0,5$ \\
\hline Toxicidade do efluente tratado & isento \\
\hline
\end{tabular}

Aplicaram-se $15 \mathrm{~L}$ de água destilada e, posteriormente, 15 L de água de reúso. Em cada uma dessas aplicações foram realizadas, a cada $5 \mathrm{~L}$, as determinações da condutividade elétrica e hidráulica do solo. Antes e após a conclusão do experimento no módulo, amostras de solo foram retiradas para análises físico-químicas. A aplicação de água destilada propunha promover a lixiviação dos íons para facilitar o entendimento da alteração da concentração iônica devido à aplicação de água de reúso.

\section{RESULTADOS E DISCUSSÃO}

Em complemento aos valores apresentados na Tabela 1 foram encontradas, na água de reúso, as seguintes concentrações de íons: nitrato $\left(16 \mathrm{mg} \mathrm{L}^{-1}\right)$, potássio $\left(15 \mathrm{mg} \mathrm{L}^{-1}\right)$, sódio (11 $\left.\mathrm{mg} \mathrm{L}^{-1}\right)$, e um valor de condutividade elétrica - CE $(0,53$ $\left.\mathrm{dS} \mathrm{m}^{-1}\right)$. Nota-se que, Paganini (2003) classifica esta água de reúso, em função do valor de CE encontrado como água de salinidade média sugerindo, quando de sua utilização, um processo de moderada lixiviação; encontrou-se, também, uma turbidez no valor de 6,2 UNT que, segundo Blum (2003) e de acordo com dados seguidos pela USEPA (1992), determina, por sua vez, os requisitos mínimos de segurança bacteriológica para a água tratada; em função deste valor encontrado, a água de reúso em questão só poderia ser utilizada na irrigação de culturas de plantas a serem consumidas cozidas ou não comestíveis.

Em relação à granulometria do solo utilizado, a Tabela 2 mostra suas características antes e após a aplicação da água de reúso.

Tabela 2. Características granulométricas do solo antes e após a aplicação da água de reúso

\begin{tabular}{lcccc}
\hline \multicolumn{1}{c}{ Amostras } & $\begin{array}{c}\text { Areia } \\
(\%)\end{array}$ & $\begin{array}{c}\text { Silte } \\
(\%)\end{array}$ & $\begin{array}{c}\text { Argila } \\
(\%)\end{array}$ & $\begin{array}{c}\text { Densidade da } \\
\text { particula } \mathbf{g ~ c m}^{-3}\end{array}$ \\
Solo antes da aplic. da água de reúso & 61,64 & 6,36 & 32 & 2,55 \\
Solo após aplic. da água de reúso & 60 & 7 & 33 & 2,60 \\
\hline
\end{tabular}

De acordo com o resultado obtido pode-se classificar este solo como areno-argiloso. Com a fração argila, segundo $\mathrm{Pa}-$ ganini (2003) é que se deve ter maior atenção, visto que altas concentrações de sódio dissolvem suas partículas, diminuem a permeabilidade do solo e dificultam o desenvolvimento do sistema radicular das plantas. Notou-se que houve variação de frações, embora insignificante.

Ainda de acordo com Paganini (2003), o controle da aplicação de água de reúso na agricultura deve ser rigoroso em função dos valores de salinidade e aplicação de sódio e de outros íons específicos. Esses valores podem ser medidos pela condutividade elétrica (CE) visto que os valores estão diretamente relacionados com as concentrações desses sais. $\mathrm{Na}$ Tabela 3 se encontram os resultados obtidos desses valores médios após a aplicação de água destilada e água de reúso.

Tabela 3. Valores médios de salinidade, sodicidade, CE, Ksat e PST no solo, após a aplicação de água destilada e água de reúso utilizando 0 método da pasta saturada (Richards, 1954)

\begin{tabular}{lcc}
\hline \multicolumn{1}{c}{ Parâmetro } & Após aplic. de água destilada & Após aplic. de água de reúso \\
Nitrato $\left(\mathrm{mg} \mathrm{L}^{-1}\right)$ & 15,33 & 14,33 \\
Potássio $\left(\mathrm{mg} \mathrm{L}^{-1}\right)$ & 8,00 & 6,66 \\
Sódio $\left(\mathrm{mg} \mathrm{L}^{-1}\right)$ & 4,00 & 15,00 \\
Ksat $\left(\mathrm{mm} \mathrm{h}^{-1}\right)$ & 32,1 & 23,0 \\
PST $\left(\mathrm{mmol} \mathrm{L}^{-1}\right)$ & 0,5 & 2 \\
$\mathrm{CE}\left(\mathrm{dS} \mathrm{m} \mathrm{m}^{-1}\right)$ & 0,07 & 0,12 \\
\hline
\end{tabular}

Observou-se que, mesmo aplicando água de reúso com valor de CE de $0,53 \mathrm{dS} \mathrm{m}^{-1}$, houve uma redução de 77,3\%, comparada ao valor encontrado de $0,12 \mathrm{dS} \mathrm{m}^{-1}$, após a aplicação dessa água no solo, embora se tendo verificado aumento dos valores de sódio em $275 \%$. Em contrapartida, os valores de CE, de acordo com a literatura australiana - EPA (1991), classificariam a água, neste momento, como sendo de salinidade baixa, permitindo seu uso para a maioria das culturas e praticamente livre da ocorrência de problemas gerados pela sua salinidade, segundo Paganini (2003). Nota-se que pode ter ocorrido retenção do íon sódio pelo solo. 
Tabela 4. Análise das propriedades químicas do solo natural e após a aplicação de água de reúso

\begin{tabular}{|c|c|c|c|c|c|c|c|c|c|c|c|c|c|c|c|}
\hline Amostra & pH & MO*** & $\mathbf{p} * *$ & $\mathrm{~K}^{*}$ & $\mathrm{Ca*}$ & Mg* & $\mathbf{H}^{+} \mathbf{A} \mathbf{l}^{*}$ & SB* & CTC* & V\% & B** & Cu** & $\mathrm{Fe}^{* *}$ & Mn** & $\mathrm{Zn}^{* *}$ \\
\hline A & 4,7 & 16 & 20 & 3,7 & 20 & 7 & 36 & 30 & 66,7 & 46 & 0,23 & 1,2 & 60 & 9,0 & 1,5 \\
\hline B & 4,8 & 15 & 20 & 3,5 & 20 & 7 & 36 & 30,5 & 66,5 & 46 & 0,20 & 1,3 & 103 & 21,0 & 10,6 \\
\hline
\end{tabular}

Métodos de extração: pH: Sol. $\mathrm{CaCl}_{2}$; M.O.: Àc.Sulfúrico; Resina: P, K, Ca, Mg; SMP - Acidez Potencial: H+Al; DTPA: micronutriente; * valores em mmoLc L ${ }^{-1}$; ** valores em mg L-1; *** valores em g L ${ }^{-1}$; Amostra $\mathrm{A}=$ solo natural; Amostra $\mathrm{B}=$ solo após aplicação de água de reúso

A condutividade elétrica (CE), monitorada pela TDR, tanto após a aplicação de água destilada quanto de água de reúso, demonstrou valores sempre abaixo dos considerados prejudicais às culturas (Figura 3 ), a qual demonstra os valores da condutividade elétrica (CE) em razão da quantidade e qualidade da água aplicada ao solo. Antes do início da aplicação de água de reúso os valores de CE se encontravam na faixa inicial de $0,09 \mathrm{dS} \mathrm{m}^{-1}$ e final de $0,06 \mathrm{dS} \mathrm{m}^{-1}$, demonstrando que ocorreu diminuição de sais em virtude do processo de lixiviação, causado pela aplicação de $15 \mathrm{~L}$ de água destilada. Durante a aplicação dos $15 \mathrm{~L}$ da água de reúso ocorreu um aumento de $0,10 \mathrm{dS} \mathrm{m}^{-1}$ até $0,14 \mathrm{dS} \mathrm{m}^{-1}$. Portanto, nota-se que o uso contínuo da água de reúso, dependendo das concentrações dos íons de sódio, pode levar ao aumento da salinidade do solo, o que prejudicaria o desenvolvimento e a produção das culturas a serem implantadas ao longo do tempo, sendo necessário promover não só lixiviações com água isenta de sais mas também o manejo do acúmulo de sais em níveis toleráveis ao sistema solo-planta.

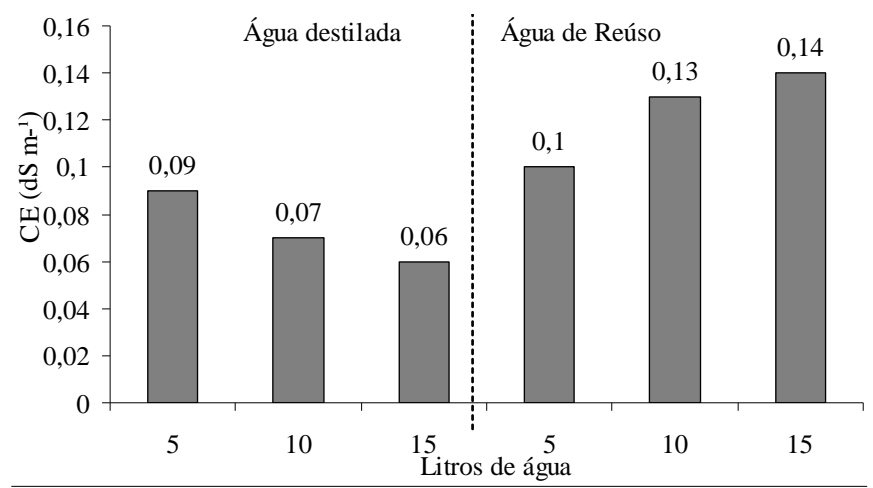

Figura 3. Valores da condutividade elétrica (CE) em razão da quantidade e qualidade da água aplicada ao solo

Constata-se, também, o aumento progressivo dos valores de sódio (Na) cujo excesso pode diminuir a permeabilidade do solo, reduzindo o processo de infiltração de água e sua absorção pela planta. Observou-se uma concentração presente de sódio na água de reúso de $9 \mathrm{mg} \mathrm{L}^{-1}$. Durante a aplicação de água destilada o solo apresentou uma concentração de 4 $\mathrm{mg} \mathrm{L}^{-1}$ e, após a aplicação de água de reúso, este valor passou a $15 \mathrm{mg} \mathrm{L}^{-1}$, demonstrando que houve uma retenção desse sódio no solo.

Os valores da porcentagem de solo trocável (PST) evidenciam o aumento deste sódio no solo; entretanto, os valores encontrados não chegam a causar limitações no uso deste solo. De acordo com Ayres \& Westcot (1991), o valor de RAS menor que 3 não indica grau algum de restrição agrícola porém o PST deve ser monitorado e corrigido, quando necessário.
Nota-se, ainda, redução da condutividade hidráulica saturada (Ksat) de $28,3 \%$, que poderia dificultar o desenvolvimento de culturas através da absorção dos nutrientes, penetração de raízes, aeração e temperatura do solo, segundo Klein \& Libardi (2002); entretanto, esta redução na condutividade hidráulica do solo em apenas dois ciclos da cultura (simulado) pode ser amenizada com a utilização de um filtro lento, antes da aplicação da água de reúso, retendo parte dos sólidos suspensos encontrados na água.

Em relação às propriedades químicas do solo, a Tabela 4 demonstra os valores encontrados do solo natural e após a aplicação de água de reúso.

Observa-se que as alterações foram maiores apenas nas concentrações de ferro (Fe), manganês (Mn) e zinco (Zn). De acordo com Crook (1993), os valores encontrados para ferro e zinco estão dentro dos recomendados pela USEPA (1999), exceto para o manganês, cujo índice recomendado seria de $0,2 \mathrm{mg} \mathrm{L}^{-1}$ a longo prazo e $10 \mathrm{mg} \mathrm{L}^{-1}$ a curto prazo; acima deste valor seria considerado tóxico para vários tipos de cultura entre alguns décimos e até algumas unidades de $\mathrm{mg} \mathrm{L}^{-1}$ em solos ácidos.

Os valores de $\mathrm{pH}$ se mantiveram quase constantes durante os dois processos, o que evidenciou que a aplicação de água de reúso não alterou suas características no solo.

Salienta-se, dentro das considerações finais, redução nos valores de nitrato, potássio e condutividade hidráulica saturada, mas aumento nos valores da CE do extrato de solução do solo, sódio, ferro, zinco e principalmente manganês. Demonstrou-se, apesar do aumento dos valores da $\mathrm{CE}$, que estes estavam sempre abaixo dos considerados prejudiciais às culturas. Embora a água de reúso aplicada possua uma CE de alto valor, houve, após sua aplicação, uma redução de $77,35 \%$, comparada com a solução do extrato do solo. Em nova observação notou-se que os valores de cálcio e de magnésio não foram alterados, o que justifica a necessidade de monitoramento constante dos teores de sódio e, consequentemente, sua correção, para evitar índices indesejáveis da PST.

\section{CONCLUSÕES}

1. A aplicação de água de reúso no solo não interfiriu nas suas características físicas.

2. Apesar da aplicação da água de reúso gerar aumentos em alguns parâmetros químicos, estes não alcançaram ainda índices que possam causar danos a algumas culturas.

3. A utilização de água de reúso em estudo para fins agronômicos deve ser aplicada de forma racional, monitorando-se principalmente a elevação do teor de sódio. 


\section{AGRADECIMENTOS}

Os autores agradecem ao Laboratório de Análise de Águas e Efluentes Líquidos, ao Laboratório de Análises de Solos e Plantas da UNITAU e ao CNPq, pelo suporte financeiro (Processos: 478421/2006 e 476146/2007).

\section{LITERATURA CITADA}

Araújo, A. L. de; Köng, A.; Milanêz, J. G.; Ceballos, B. S. O. de. Reúso indireto de esgotos na irrigação de colunas experimentais de solo cultivados com alface (Lactuca sativa, L.).; In: Congresso Brasileiro de Engenharia Sanitária e Ambiental, 20, Rio de Janeiro. Anais... Rio de Janeiro: ABES, 1999. 8p.

Ayres, R. S.; Westcot, D.W. A qualidade da água na agricultura. Campina Grande: UFPB, 1991. 218p.

Baumgartner, D.; Sampaio, S. C.; Silva, T. R. da; Teo, C. R. P. A.; Vilas Boas, M. A. Reúso de águas residuárias da piscicultura e da suinocultura na irrigação da cultura da alface. Engenharia Agrícola, v.27, n.1, p.152-163, 2007.

Blum, J. R. C. Critérios e padrões de qualidade da água. In: Mancuso, P. C. S.; Santos, H. F. dos; Philippi Jr, A (coord.) Reúso de Água. Barueri: Manole, 2003. 49p.

Bond, W. J. Effluent irrigation - an environmental challenge for soil science. Australian Journal of Soil Research, v.36, p.543555, 1998.

Crook, J. Critérios de qualidade da água de reúso. Revista DAE, v.174, p.8-10, 1993.

EMBRAPA - Empresa Brasileira de Pesquisa Agropecuária. Sistema Brasileiro de Classificação de Solos. Brasília: Embrapa Produção de Informação; Rio de Janeiro: Embrapa Solos, 1999. 412p.

EPA - Environmental Protection Agency. In: National Primary Drinking Water Regulations Current Driking Water Standards. Office of Water. 1991.

Fiori, M. G. S.; Smaniotto, A.; Malmann, L.; Dieter, J.; Sampaio, S. C.; Nobrega, L.H. Modificações na densidade do solo cultivado com milho frente ao uso de água residuária da suinocultura. In: Congresso Brasileiro de Engenharia Agrícola, 36, 2007, Bonito. Anais... Bonito: SBEA, 2007., CD-Rom.

Hespanhol, I. Potencial de reúso de água no Brasil: Agricultura, indústria, município e recarga de aqüíferos. In: Reúso de água. Mancuso, P. C. S.; Santos, H. F. dos; Phillippi Jr.,, A. (coord.). Barueri: Manole, 2003. 58p.

Klein, V. A.; Libardi, P. L . Densidade e distribuição do diâmetro dos poros de um Latossolo Vermelho, sob diferentes sistemas de uso e manejo. Revista Brasileira de Ciência do Solo, v.26, p.857-867, 2002 .
Mancuso, P. C. S.; Santos, H. F. dos. A escassez e o reúso de água em âmbito mundial. In: Reúso de água. Mancuso, P. C. S.; Santos, H. F. dos; Philippi Jr.,, A. (coord.). Barueri: Manole, 2003. 18p.

Mehnert, D. U. Reúso de efluente doméstico na agricultura e a contaminação ambiental por vírus entéricos humanos. Biológico, v.65, n.1/2, p.19-21, 2003.

Miranda, F. R. de; Souza Jr.,; F. E. A.; Lima, R.N. de; Crisóstomo, L.A.; Santana, M. G. S. de; Reúso de efluentes da carcinicultura de águas interiores na irrigação do arroz: estudo das alterações químicas no solo. In: Congresso Brasileiro de Engenharia Agrícola, 36, 2007, Bonito. Anais... Bonito: SBEA, 2007. CD-Rom

Mmolawa, K.; Or, D. Root zone solute dynamics under drip irrigation: A review. Plant and Soil, v.2, p.163-190, 2000.

Paganini, W. da S. Reúso da água na agricultura. In: Reúso de água. Mancuso, P. C. S.; Santos, H. F. dos; Philippi Jr, A. (coord.). Barueri: Manole, 2003. 62p.

Reichardt, K.; Timm, L.C. Solo, planta e atmosfera: Conceitos, processos e aplicações. Barueri: Manole, 1.ed. 2004. 500p.

Reis, L. B. dos; Fadigas, E. A. A.; Carvalho, C. E. Energia, recursos naturais e a prática do desenvolvimento sustentável. Barueri: Manole, 2005. 41p.

Ribas, T. B. C; Fortes Neto, P. Avaliação do desempenho da estação de tratamento de esgoto compacta por leito de raízes implantada no município de Jacareí/SP. In: Congresso de Saúde e Qualidade de Vida do Cone Leste Paulista, 4, 2006, São José dos Campos. Anais...São José dos Campos: UNIVAP, 2006. CD-Rom

Richards, L. A. Diagnosis and improvement of saline and alkali soils. Washington: United States Salinity Laboratory, 1954. 160p. Agriculture Handbook.

Santos, S. R dos; Pereira, G. M. Comportamento da alface tipo americana sob diferentes tensões da água no solo, em ambiente protegido. Engenharia Agrícola, v.24, n.3, p.569-577, 2004.

Souza, C. F.; Folegatti, M. V.; Matsura, E. E.; Or, D. Calibração da Reflectometria no Domínio do Tempo (TDR) para a estimativa da concentração da solução no solo. Engenharia Agrícola, v.26, n.1, p.282-291,- 2006a.

Souza, C. F.; Matsura, E. E.; Folegatti, M. V.; Coelho, E. F.; Or, D. Sondas de TDR para a estimativa da umidade e da condutividade elétrica do solo. Irriga, v.11, n.1, p.12-25, 2006b.

Souza, J. T.; Leite, V. D.; Luna, J. G. de. Desempenho da cultura do arroz irrigado com esgotos sanitários previamente tratados. Revista Brasileira de Engenharia Agrícola e Ambiental, v.5, n.1, p.107-110, 2001.

USEPA - US Environmental Protection Agency. In: Guidelines for water reuse. Washington: USEPA. 1992. 445p. 